\title{
A systematic review of sovereign connectedness on emerging economies ${ }^{\text {th }}$
}

\author{
Laura Ballester $^{\mathrm{a}, *}$, Ana Carmen Díaz-Mendoza ${ }^{\mathrm{b}}$, Ana González-Urteaga ${ }^{\mathrm{c}}$ \\ ${ }^{\mathrm{a}}$ University of Valencia, Spain \\ ${ }^{\mathrm{b}}$ University of La Rioja, Spain \\ ${ }^{\mathrm{c}}$ Public University of Navarre and Institute for Advanced Research in Business and Economics, INARBE, Spain
}

A R T I C L E I N F O

\section{Keywords:}

Contagion

Emerging markets

Crisis

Cross-market correlations

\begin{abstract}
A B S T R A C T
This article systematically reviews the academic literature on emerging market contagion in order to summarize what we have learnt about the transmission channels existing in these countries. Given the large body of academic research focused on this topic, we especially direct our attention to the strand of the literature that defines and empirically analyses this topic as the significant increase in the cross-market correlations between asset returns during crisis periods or when a shock occurs. The survey covers the findings on financial contagion in the stock, bond, exchange and credit default swap markets during a large period that covers several crises that have characterized the related literature, such as the currency crises of the 1990s, the global financial crisis and the Eurozone debt crisis. Finally, new topics are identified, serving as an outline for future research.
\end{abstract}

\section{Introduction}

Prior to the 1990s, professionals and academics had seen economic and financial crises as events that exclusively affected those markets that had suffered the origin of the financial turbulence. Since the mid1990s, however, many crises that began in emerging markets have been characterized to a great extent by the phenomenon of contagion. The Mexican currency crisis (1994-1995) is one example. In the first place, the impact on the Mexican market was devastating, and then it spread worldwide. A few years later, the Asian crisis (1997-1998) affected many Asian countries and contributed to the Russian default in 1998. The Brazilian (1999), Turkish (2001) and Argentinean (2002) crises have also been distinguished as being transmitters of contagion, leading to a highly unstable international financial system. As noted in Masson (1999), a common element observed as a consequence of the different crises is that the contagion of the crisis across emerging economies has impacted countries with seemingly low correlated economic fundamentals.

Later, the global downturn of 2007-2009 hit the world economy in an overwhelming way. In contrast to previous financial crises, it was the first crisis in recent history that was triggered by problems in the US economy, viewed as the largest and most powerful market around the word. However, also in this case, the worldwide financial contagion was evident and even more pronounced than in previous crises (Ozkan \& Unsal, 2012). From the viewpoint of an emerging economy, the beginning was different from previous crises. The severe liquidity constraints of the developed economies produced a sharp reduction in capital inflows. Furthermore, emerging countries experienced a substantial drop in their exports as a result of the decline in consumption in the advanced economies due to the crisis. Although the source of instability may have been different from the crises of the 1990s, given that the global downturn of 2008-2009 started in a developed economy, the effects of the crisis for emerging economies have been somewhat similar: an unexpected stop of capital inflows followed by an economic crisis (Darolles, Dudek, \& Le Fol, 2015).

This background makes clear that something that occurs in one economy is often no longer a mere domestic event. In increasingly interconnected financial markets, its implications can extend quickly to the entire global system, with devastating effects. The intensity of the global financial crisis highlighted the understanding that contagion is key to learning about financial crises and their evolution. As a consequence, the literature of contagion has reignited in the last decade. Researchers started focusing mainly on analysing the risk transfer from the US to other advanced economies (see for example Ballester, Casu, \& González-Urteaga, 2016; Bekaert, Ehrmann, Fratzscher, \& Mehl, 2014; Reinhart \& Rogoff, 2008). The subsequent European debt crisis marked

\footnotetext{
The authors would like to express their gratitude to Brian Lucey, Maurice Peat, Sam Vigne, the participants at the IRFA Meta Analysis and Systematic Reviews in

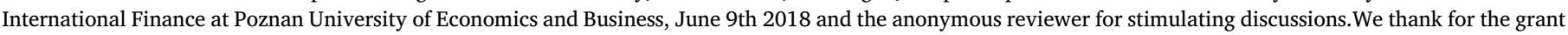

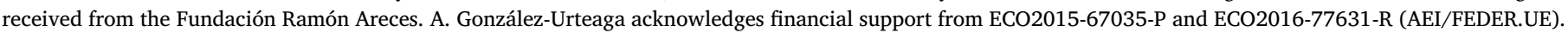

* Corresponding author.

E-mail addresses: Laura.Ballester@uv.es (L. Ballester), ana-carmen.diaz@unirioja.es (A.C. Díaz-Mendoza), ana.gonzalezu@unavarra.es (A. González-Urteaga).
} 
the beginning of sovereign contagion studies in Europe (Caporin, Pelizzon, Ravazzolo, \& Rigobon, 2018; Martin-Bujack \& Corzo, 2016). However, despite the unquestionable relevance of sovereign contagion in emerging economies, they have not received as much attention after the global financial crisis.

Following the previous idea, in this systematic review we focus on the analysis of contagion exclusively in emerging markets. The study of financial contagion is a relevant subject for the financial economy; however, it includes a large set of different definitions and empirical measures. In this paper, we review the most significant papers that approach the idea of contagion as the significant cross-market linkages during crisis periods (Forbes \& Rigobon, 2002) or the magnitude of cross-market co-movements between financial asset returns that exceed what is justified by macroeconomic fundamentals (Eichengreen, Rose, \& Wyplosz, 1996). Our goal is twofold. First, we want to address the importance of understanding the mechanisms and evolution of contagion in emerging markets given its role in global financial instability. Second, we aim to discuss a topic that needs more dedicated attention and represents an open subject for future academic work.

The growing relevance of emerging market economies for the global economy is undeniable. These markets have experienced a consistently high level of economic development, becoming one of the main engines of world growth. Moreover, it is accompanied by high financial returns linked to powerful corporate income growth. In fact, given the moderate level of cross-market correlation with developed countries, they have offered a great opportunity in terms of portfolio diversification. Along this line, some papers published after the global crisis, such as Christoffersen, Errunza, Jacobs, and Langlois (2012), affirm that although emerging economies have increased the correlation structure with mature markets, they still present significant advantages for international diversification.

In addition to that, emerging sovereigns are among the largest highyield borrowers in the world. Debt and budget deficits have increased among emerging economies since the global financial crisis, making them more vulnerable to a sharp rise in borrowing costs. In this sense, some empirical analyses (Dooley \& Hutchison, 2009; Martinez \& Ramirez, 2011; Samarakoon, 2011) show that emerging regions are very exposed to global and regional shocks and are particularly unstable when compared to advanced economies. As noted by Darolles et al. (2015), emerging markets present some inherently special features compared to developed countries that make these economies more risky. Specifically, these risks are political, currency, liquidity, extreme returns, contagion, and even systemic. These particular characteristics have increased the importance of emerging markets to industry, to academia and to other stakeholders.

Therefore, this paper conducts a systematic review that analyses the financial connection and transfer of risk in emerging markets. As far as we know, this is the first paper that reviews this relevant topic, taking into account not only the initial literature that motivated the study of contagion between emerging markets but also the literature that revived the subject in the wake of the global financial crisis, between emerging economies and also between the US and emerging markets. We improve the current literature in two ways. First, we determine what we have learnt about the contagion relationships affecting the emerging economies from the 1990s to the 2007-2009 financial crisis. Second, we identify some remaining gaps, suggesting directions for future research to be addressed by researchers.

The remaining paper is organized as follows. Section 2 provides the theoretical framework for the definition of contagion considered in the present systematic review. Section 3 explains how the search has been carried out to select the final set of research papers considered for the present study. Section 4 discusses the findings from the review of the initial papers corresponding to the period prior to the global financial crisis, whereas Section 5 reviews the most recent literature covering the period from the global financial crisis to the present. Finally, Section 6 offers our conclusions and suggestions for future research to be addressed by researchers.

\section{Theoretical framework of the financial contagion approach used}

The result almost immediately after a financial crisis in a given country (or region) is that it can affect other international markets around the world. This is what is known in academia as contagion, connection, interdependence, transmission, spillover or any other concept that reflects the fact that a specific country becomes vulnerable as a result of financial distress in a given country. As noted by Stiglitz (2010), financial contagion after a large negative shock is the other side of the same coin of the financial integration of international financial markets. This financial globalization has strengthened the trade and financial channels through which countries are interconnected. This is the key idea in the general contagion definition that we follow in this paper, which tries to distinguish contagion from "high transmission during all the sample period" (interdependence by Forbes \& Rigobon, 2002). We refer to the latter concept as the spillover that reflects changes in a specific market due to the transmission of market specific information from one market to another (Fleming, Kirby, \& Ostdiek, 1998).

Although contagion is a very intuitive concept that is related to the cross-market linkages between financial asset returns, over the last twenty years there has been a lively academic discussion about what constitutes contagion and how it should be defined (see, for example, Kaminsky \& Reinhart, 2000; Dornbusch, Park, \& Claessens, 2000; Pericoli \& Sbracia, 2003). Nowadays, financial contagion literature, and in particular the works that focus on emerging markets, covers a huge sample of theoretical and empirical papers with different definitions and measures of contagion. For this reason, it is necessary to first provide a certain theoretical framework of the topic of contagion so that we can then focus on a concrete approach to the definition of contagion.

Specifically, we review relevant empirical papers that analyse sovereign emerging financial contagion in terms of cross-market linkages through financial asset correlations. If the findings support an increase in the structure of the financial asset correlation of different countries, the existence of contagion or the transmission effect was assumed. However, the academic literature has added an important nuance. Cross-market linkages need to be tested by analysing whether the correlation coefficients between countries increase significantly, but comparing turbulent and tranquil periods. Nevertheless, the literature that uses previous definitions to analyse whether or not there is evidence of contagion is not exempt from criticism. The seminar paper of Forbes and Rigobon (2002) argues that the usual contagion tests based on correlations should take into account the time varying volatility in order to correct the bias produced by heteroscedasticity. ${ }^{1}$ They call contagion "shift-contagion", which reflects significant changes in the transmission mechanisms during crisis periods due to a specific shock between countries that is not related to an exogenous common shock that affects all countries. Some references that also follow this definition are Kaminsky, Reinhart, and Vegh (2003) and Longstaff (2010), among others.

In addition, as indicated by Eichengreen et al. (1996), among others, correlation estimation must control for some country variables to identify pure contagion. If two markets are traditionally highly correlated, then one can naturally expect a change in one market in response to a sharp change in the other market. In other words, our contagion approach is also defined as the magnitude of cross-market linkages between asset returns that transcend what is justified by financial and economic fundamentals, taking into account their evolution over time (Bekaert et al., 2014). This latest concept follows the above definition of contagion because interdependence is the transmission

\footnotetext{
${ }^{1}$ Ribogon (2003a) also adds other important bias to take into account in cross-market correlation estimations.
} 
mechanism best explained by the fundamentals.

Although the most recent literature (Hwang, In, \& Kim, 2010, among others) has confirmed that cross-market correlation is not the appropriate methodology to measure contagion, newer, more sophisticated methods have been developed in order to avoid the limitations in correlation frameworks. Nevertheless, it is important to note that the papers included in this systematic review follow the previous definitions of contagion explained above, independently of the methodology used.

\section{Systematic review method}

The search for relevant articles is carried out in the online databases of Web of Science (WoS) and Scopus. The initial search criterion is based on selecting those papers that contain the words "contagion" AND "emerging market" AND "crisis" or "contagion" AND "emerging market" AND "sovereign" in the title, the abstract or the list of keywords. We look into the "Business Finance" category and article or book chapter documents. We consider papers published for the period beginning from the year 1990 to the year 2018, with the aim of covering both the initial papers of contagion in emerging markets related to the crises of the 1990s, as well as the more recent literature mainly related to the impact of the global financial crisis in emerging economies. At a preliminary stage, all duplicate copies in both sources are removed. With this criterion, the initial search produces 172 research papers to be reviewed for the period 1990-2018.

In the second stage, we remove some papers from the initial list, either because the financial contagion was not their main research topic, or because despite analysing contagion they used a different approach (to define contagion) to the one we have explained in the previous section. Additionally, we discard all those papers that focus on volatility spillovers, or that analyse contagion at the firm level instead of at the country level, including those that focus on the banking sector or those that study the relationship between the banking and the sovereign sectors. We also eliminate some research papers that consider changes on rating events as the source of contagion. This last part of the screening process is done by reviewing the full text of each paper. After that, the number of research papers considered for the present systematic review is reduced to 45 . We have classified 18 corresponding to the period prior to the global financial crisis and 27 after it.

\section{Emerging market connectedness: results for the initial literature}

The first studies that analyse contagion exclusively for emerging markets surfaced as a result of the financial crises in the 1990s, with the Mexican currency crisis (1994) and the Asian crisis (1997) being the two on which researchers have focused the most attention. As Calvo and Reinhart (1996) indicate, until that moment, limited information had been written in the literature about how specific countries are transmitters (receivers) of developments to (from) their neighbouring countries and how important financial markets are in the risk transmission process. Both crises emphasised the fact that financial problems in a given country or regional zone can be easily transmitted to the financial markets of other countries, either their geographical neighbours or countries completely different in terms of economic fundamentals and financial institutions.

The initial papers focused on studying contagion are based on crossmarket correlations between financial markets across economies. In this line, one of the first studies focusing on co-movements between Asia and Latin America in the context of the 1994 Mexican crisis is Calvo and Reinhart (1996). Their findings show that co-movements in equity and bond markets increased significantly in the wake of the Mexican crisis. This result is viewed by the authors as an indication of the contagion effect, given the difference in the macroeconomic fundamentals across these countries. They also find differing regional patterns, suggesting regional rather than global contagion.

A few years later, the literature analysed whether cross-market correlation coefficients increase significantly, but comparing periods of crisis with stable periods. In this context, Baig and Goldfajn (1999) look for evidence of contagion ${ }^{2}$ during the Asian crisis among Asian emerging economies. In addition to the stock market, they also consider foreign exchange rates, interest rates, as well as the sovereign debt market. They find that only foreign exchange and debt market correlations increase significantly. However, if the domestic and common shocks on selected markets are taken into account, the results show a high and statistically significant cross-border contagion in exchange rates and the stock market. Also focusing on the Asian crisis, Park and Song (2001) consider the exchange and stock markets for eight Asian countries. They follow the definition of contagion and the methodology of Baig and Goldfajn (1999); however, they extend the country sample by adding Hong Kong, Singapore and Taiwan. Moreover, their objective is to focus on contagion among East Asian countries after discounting the common effects that come from Southeast Asian countries. Their findings show that in the first instance, the Southeast Asian crisis was transmitted to the East Asian countries with particular damage for Taiwan where foreign investors worried about the financial instability in this country concluded that Hong Kong and Korea were equally vulnerable.

Taking both the Mexican and Asian crises into account, Masson (1999) looks for the motivation and linkages that cause contagion. Although the methodology used is not based on correlation analysis, the aim of the paper is to identify the sources that explain contagion beyond the fundamentals, specifically trade, economic activity and competitiveness. In this sense, the results suggest that it is important to take into account: financial intermediation, maturity of government debt, rollover risk, the role of government guarantees on deposits and private foreign borrowing, and self-fulfilling expectations of volatility.

After considering the time varying volatility presented in crisis periods usually found in the financial data, Forbes and Rigobon (2002) provide evidence of stock market contagion for a large number of countries and three periods of financial distress: the 1994 Mexican crisis, the 1997 Asian crisis and the 1987 US crash. The results indicate the existence of interdependence instead of contagion. During both turbulent and tranquil periods, a great increase in market co-movement is found. In parallel, in an unpublished but notable paper, Forbes and Rigobon (2000) discuss and analyse shift-contagion, focusing on Latin American stock and bond markets and covering several financial crises from 1994 to 1999 . Their results are totally in line with Forbes and Rigobon (2002). Moreover, the cross-market co-movement is higher among other emerging markets than among Latin American countries. ${ }^{3}$ Along the same line, Rigobon (2003a) finds for a large sample of stock markets that the transmission effect for stock markets in emerging and developed countries is stable during the Mexican crisis, while for the Russian collapse, and to a greater extent for the Asian crises, significant shift-contagion is observed.

Adopting a similar model to the one used in Forbes and Rigobon (2002), Dungey, Fry, Gonzalez-Hermosillo, and Martin (2006) find some evidence of contagion in two concrete events produced in the Russian crisis. ${ }^{4}$ The contribution of the transmission effect in these events experienced by Asia, Latin America, Europe and the US to total

\footnotetext{
${ }^{2}$ They also estimate vector autoregressive models in order to estimate the impulse response functions with respect to shocks. This allows the authors to observe not only if there was a significant transmission in each market, but also to measure the persistence of shocks.

${ }^{3}$ The authors conduct contagion tests that address heteroscedasticity, endogeneity, and omitted variables bias, reviewing alternative approaches existing in the literature.

${ }^{4}$ The two events are the 1998 Russian bond default and the Long-Term Capital Management (LTCM) recapitalization announcement in the following month.
} 
volatility in bond spreads is about $17 \%$. Moreover, the evidence supports the regional nature of the contagion effects observed in the Eastern European countries. Finally, the effect of contagion is not significantly different between emerging and developed markets, with the level of volatility in the emerging economies being mostly higher than in the latter markets. In contrast, Martinez and Ramirez (2011) analyse the reactions of the asset markets of Latin American countries to international shocks and conclude that there is no financial contagion. The paper distinguishes between contagion and interdependence based on the sensitivity of asset markets to shocks, specifically exchange rates, interest rates, equity and bond spreads. An extreme market reaction signifies contagion, while a moderate response implies interdependence. In particular, their findings suggest interdependence across asset markets. Additionally, they also found extreme cases of asset markets isolated from regional trends, represented by Argentina, Uruguay and Venezuela.

However, as noted previously by Bae, Karolyi, and Stulz (2003), among others, the previous literature focused on asset return correlations to measure contagion has an important limitation, given that these correlations did not reflect the real dependence structure of financial markets. ${ }^{5}$ Following this idea, some studies have improved the asset correlation models to study contagion.

The literature refers to conditional correlation analysis in the models that correct the correlations trying to capture the real link between financial returns. Following the methodological advantages in Forbes and Rigobon (2002) and Rigobon (2003b), Caporale, Cipollini, and Spagnolo (2005) analyse the existence of a significant increase in the cross-market co-movement within Asian stock returns during the aftermath of the Asian crisis. Their objective is to determine if the transmission observed is due to contagion or interdependence. The results show signs of contagion within the East Asian countries. The contagion results are comparable with the results from studies that examine Asian countries within the Asian crisis and use conditional models. In this vein, the results are opposite to the ones reported by Forbes and Rigobon (2000, 2002) but in line with Park and Song (2001) and Rigobon (2003a). Following the same estimation method and contagion definition as Caporale et al. (2005), Arestis, Caporale, Cipollini, and Spagnolo (2005) examine whether there was any stock market contagion from East Asian markets to a number of non-emerging countries. Until this moment, this has been the only paper that analyses the connection between emerging and developed countries. The findings show that contagion from Asia to developed countries was limited, except for Japan. The authors explain the existence of this transmission as being due to Japan's role as a main lender in the Asian region. The same result is found in Hyde, Bredin, and Nguyen (2007) by applying an asymmetric dynamic conditional correlation model to equity markets in the Asia-Pacific region, Europe and the US. The evidence shows that co-movements between Asia and developed countries do not increase significantly during the Asian crisis, except at the beginning of the year 2000. Nevertheless, a significant rise across the correlations of Asian countries is observed.

Applying the same methodological framework to exclusively Asian stock indices, Chiang, Jeon, and Li (2007) find the same result as previous authors regarding the Asian region, i.e. that a contagion effect exists. Moreover, structural changes in the stock market return correlation are found. The authors identify two distinct phases related to the contagion effect of the Asian crisis. First, they observe evidence of contagion accompanied by higher correlations (second half of 1997-1998), and then they note a herding behaviour caused by continuous high correlations (during the year 1998). This implies that the benefits of international portfolio diversification are reduced. In addition, credit rating changes are determinants of the correlation

\footnotetext{
${ }^{5}$ Dungey and Zhumabekova (2001) offer a detailed explanation of the caveats of the cross-market correlation framework.
}

coefficients in its own and foreign markets.

Other works in the literature have applied models based on extreme value theory. The reason for measuring contagion with this approach is to analyse the joint behaviour of asset financial returns of different markets that exceed some threshold. In addition, it allows for the testing of the asymmetric effect in contagion for positive and negative extreme returns. Focusing on Latin American and Asian countries, Bae et al. (2003) test for stock market contagion both between and within regions, as well as its economic significance and potential sources. During the $1992-2000$ period, the results suggest that contagion is different in both regions. Contagion from Latin America to other countries (and within the region) is higher than contagion from Asian countries and is explained by interest rates, changes in exchange rates, and conditional stock volatility returns. Regarding asymmetric effects, large negative returns are more significant than extreme positive returns. These results are in line with those of Rodriguez (2007) who finds signs of contagion in Asian and Latin American emerging market stock indices during the Asian and Mexican crises using the copula approach. Chan-Lau, Mathieson, and Yao (2004), who also include developed countries in their contagion study, find, in line with previous authors, that equity market contagion is statistically different in Latin American and Asian regions and greater for the extreme negative returns. The results regarding inter-regional contagion shows strong contagion from the US to Latin America, though it is only significant after the 1998 Russian crisis. Using two different global extreme indicators, the findings indicate that within this region is where the highest growth in contagious relationships exists.

The opposite result is found in Fazio (2007). The author estimates a model that includes the importance of the fundamentals during the 1990s with the aim of distinguishing between extreme contagion and extreme interdependence using exchange market pressure indices. The sample consists of not only Latin American and Asian countries but also Central-Eastern European countries. The paper concludes that the extreme relationship observed between countries is mostly related to extreme interdependence that is explained by economic fundamentals. The exceptions that exhibit pure contagion are countries that are in the same region (Malaysia and Philippines; Argentina and Mexico; Argentina and Venezuela).

An alternative methodology to test the evidence of financial market cross-market correlations is to use the Markov regime-switching model, which captures the dynamic of the returns including the structural breaks that are intrinsically established by the data. Following this method and focusing on the Asian crisis, Boyer, Kumagai, and Yuan (2006) find results that go against those of Fazio (2007), concluding that the stock market cross-market correlation structure is due to investor asset holdings rather than fundamentals.

\section{Emerging market connectedness: evidence from the 2007-2009 global financial crisis to the present}

Although there is a wide range of literature that focuses on analysing financial contagion in terms of the several crises that took place in the 1990s, the research as a result of the 2007-2009 turmoil is still growing. The devastating effects of contagion on developed countries during the so-called global financial crisis (GFC, hereafter) have been extensively documented. In fact, early studies analysing the effects of the GFC mainly focus on the developed markets, although more and more authors are turning towards the emerging economies. On the one hand, some authors highlight the fact that emerging markets have become an increasingly important asset class for investors given their role in the diversification of international portfolios (Horváth, Lyócsa, \& Baumöhl, 2018; Kenourgios \& Dimitriou, 2015; Samarakoon, 2011). On the other hand, although, as indicated by Martinez and Ramirez (2011), the spread of shocks is not directly related to the level of development of the countries, the greater vulnerability of the emerging economies to the contagion effects has led researchers to study these types of cases. 
Samarakoon (2011) also notes that during the most turbulent episode of the GFC that lasted approximately six months from September 2008 to the beginning of March 2009, the US stock market dropped sharply by $43 \%$, that of emerging markets by $50 \%$, and that of frontier markets by $60 \%$. This argument is backed by several authors, such as Dooley and Hutchison (2009) and Dimitriou, Kenourgios, and Simos (2013), whose findings suggest signs of isolation in the case of the emerging countries during the early stages of the crisis, but as of autumn 2008, they start to respond powerfully to the worsening situation in the US markets and the real economy. All this has exposed the vulnerability of emerging markets to financial contagion during a crisis and has fuelled the literature on the subject. Therefore, the objective of this section is to review the existing empirical research on contagion that arose from the GFC, paying special attention to the impact that the crisis had on emerging countries.

Researchers have looked for contagion or spillover effects for alternative financial markets, but paying special attention to the stock market. We have found many studies that have analysed this issue using alternative methodologies, such as conditional correlations, ARCH/ GARCH or VAR models, with the aim of determining whether or not there is contagion in returns. Naoui, Liouane, and Brahim (2010) consider six European developed stock markets and ten emerging ones and look for contagion during the US subprime crisis, for which they use a conditional correlation model. They conclude that, during the subprime crisis, contagion from the US is strong not only to developed countries, but also to the emerging countries, with a greater effect for South America than for Asia. Kenourgios and Dimitriou (2015) support this result, concluding that Latin America is the most affected region in terms of contagion during the GFC. Making use of an asymmetric generalized model, Kenourgios and Padhi (2012) come to an opposite conclusion. They observe contagion from US during the GFC in the case of nine emerging economies; however, Latin American countries appear to be less affected than Asians. In addition, they conclude that the crisis is transmitted more intensely in the case of stocks than for bonds.

With respect to other papers that estimate conditional correlations using ARCH/GARCH or VAR models in order to explore the connectedness between financial markets, the main conclusion is almost unanimous regarding the existence of contagion. Overall, they all conclude that the US subprime crisis extended to emerging economies with greater or lesser impact depending on various factors. Hwang et al. (2010) consider international stock market data for a large set of countries (15 emerging and 23 developed). In a nutshell, they find evidence of financial contagion regardless of the level of development of the country, but with more pronounced effects during the GFC than in previous crises, such as the East Asian crisis. Celik (2012) also shows evidence of contagion in the case of currencies for most of the ten emerging and nine developed countries considered. However, the author also notes that contagion had a more pronounced influence on emerging economies, which reflects the greater instability of emerging economies with respect to developed ones. Similarly, Tzeng and Tay (2014), for a sample of 16 emerging countries, and Yamamoto (2014), for the case of four Asian emerging countries, report a significant contagion effect from the US to the considered stock markets.

Another group of papers attempts to identify the source of specific channels or factors that affect the vulnerability of emerging countries in relation to the GFC. Kim, Kim, and Lee (2015) provide insights into the channels of contagion from the US subprime crisis on five emerging Asian countries. Their findings identify some important factors as determinants of contagion, such as foreign investment in the case of equity markets, and the dollar Libor-OIS spread and the sovereign CDS premium and foreign investment in the case of foreign exchange markets. Aloui, Ben Aïssa, and Nguyen (2011) adopt a different approach and use copulas in order to capture the dynamic patters of returns and cross-market linkages. The authors document a significant dependence on the US for all the BRIC emerging stock markets, although they also observe lower levels of interconnection between emerging markets in periods of recessions compared to quiet periods, which decreases the probability of simultaneous crashes. Additionally, they attempt to provide evidence of which economic indicators are relevant in the observed contagion, concluding that the effect is greater for the markets that depend on commodity prices (Brazil and Russia) than for the markets more oriented towards the export of finished products (China and India). Conversely, the findings of Dimitriou et al. (2013) suggest that the contagion from the US subprime crisis to the stock markets of the BRIC countries does not seem to be related to their commercial and financial characteristics.

Along the same line, Neaime (2012) identifies the non-oil producing MENA countries as those most affected by contagion and concludes that their greater dependence on external resources (with high exposure to banks and equity markets in developed countries of the US and Europe), their still weak regional trade and greater financial integration are factors that have contributed to intensifying contagion in these cases. Adopting a sample of ten developed and emerging economies, Luchtenberg and Vu (2015) list different variables related to economic fundamentals and regional effects as determinants of contagion. In particular, they find that trade structure, interest rates, inflation rates, industrial production and the risk aversion of investors contribute to financial contagion.

Other authors, such as Ammer, Cai, and Scotti (2011), examine a broad set of 27 emerging stock markets (located in Asia, Europe, the Middle-East, Africa and South America) and, although they do find evidence of contagion, they show that its effect is substantially lower than in previous crises. The authors state that this is due to the improvements made by the emerging countries in their fundamentals prior to the GFC. More specifically, they point out that the establishment of flexible exchange rates instead of fixed rates has been decisive. Conversely, the results of Horváth et al. (2018) support the idea that the monetary policy adopted by emerging countries does not influence contagion, but rather it is the over-reactions of investors that is behind it. They consider six Central and Eastern European emerging countries and identify contagion by employing quantile regressions.

Notwithstanding the foregoing, some authors disagree and show contradictory results regarding the general evidence. Samarakoon (2011) considers an extensive set of 62 emerging countries $^{6}$ and comes to the conclusion that the shocks that occurred in emerging markets are those that spread to the US. In fact, with the exception of Latin America, they do not observe contagion from the US crisis to emerging markets, whereas there is strong contagion in the opposite direction. Arouri, Jawadi, and Nguyen (2010) go further and conclude that, although the emerging countries show a great dependence on the US, there is no evidence of contagion, given the insignificant changes observed in cross-market linkages in crisis times. Their sample consists of monthly data from MSCI stock market indices of Mexico, Argentina, South Korea and Thailand for a period between 1987 and 2009. Similarly, Gupta and Guidi (2012) find weak signs of contagion in the case of India and conclude that India has remained relatively isolated, not only from US but also from other developed Asian economies (namely Hong Kong, Japan and Singapore).

So far, our literature review has collected the works that investigate financial contagion in the wake of the global financial crisis focusing mostly on the stock market. However, the crisis led to another important strand of the literature concerned with credit risk transmission. Many researchers became interested in understanding the linkages between sovereign and/or bank credit risk, paying special attention to developed countries such as the US or Europe. However, far less attention has been given to the analysis of credit risk transmission on the emerging economies, which has mainly focused on sovereign credit

\footnotetext{
${ }^{6}$ More specifically, they distinguish between emerging and frontier countries based on the Standard and Poor's classification as of May 2009, what leads them to consider 22 emerging and 40 frontier countries.
} 
risk.

Dooley and Hutchison (2009) make use of the sovereign CDS spreads of fourteen emerging countries and find a strong contagion effect from the US during the GFC, despite the monetary policy measures carried out by emerging countries. Along the same lines, using sovereign bonds and CDSs, Darolles, Dudek, and Le Fol (2013) detect contagion in nine emerging economies, but as a result of a liquidity problem rather than from fundamentals. Thus, they argue that this additional liquidity risk should be closely monitored by fund managers. In contrast, due to the increasing integration of emerging markets to the global economy, Kang and Suh (2015) examine to what extent the financial turmoil experienced by emerging markets in 2013-2014 spread to advanced economies creating what they call reverse-spillovers. They consider sovereign CDSs for a broad battery of advanced and emerging markets and they obtain findings that support their hypothesis. Additionally, the authors identify the trade and economic linkages as a significant factor determining credit risk contagion in line with the findings of Neaime (2012) and Luchtenberg and Vu (2015) for the stock market.

The Eurozone sovereign debt crisis (EDC, hereafter), which began in late 2009, revived the credit risk contagion literature. This was mainly focused on the European markets, but several authors have also analysed the effects that the debt problems of some European countries, together with the GFC, have had on international emerging economies. de Boyrie and Pavlova (2016) document significant contagion between fourteen emerging CDS markets from 2010 to 2014. Similarly, the findings of Ballester and Gonzalez-Urteaga (2017) support the existence of cross-border contagion across sovereign CDS Latin American emerging economies.

Hassan, Hoque, and Gasbarro (2017) consider CDS data from fifteen emerging countries and find different contagion patterns depending on the region considered. While Europe and Latin America appear to be highly affected by the negative shocks produced during the GFC and the EDC, Asia seems to be isolated from the negative events that occurred outside the region. At the intra-region level, they detect strong evidence of contagion among Asian emerging countries. Cho, Choi, and Chung (2014) find a similar result by analysing the connectedness between sovereign CDSs for six Asian emerging countries. They find evidence of contagion that tends to intensify during times of extreme financial instability (such as the Lehman Brothers bankruptcy in 2008, the EDC in late 2009 and the US credit downgrade in 2011).

Studying exclusively the case of the EDC, Samarakoon (2017) considers a broad set of advanced and emerging countries and documents a significant negative contagion for both the stock and bond markets. In line with the Hassan et al. (2017) results for the CDS market, Asia is the only region that appears to be immune to the debt problems of several countries in the Eurozone. This result is also supported by Mollah, Quoreshi, and Zafirov (2016) and Beirne and Fratzscher (2013). They both document an absence of contagion for Asia during the EDC. However, the former generally find evidence of contagion from the US to 55 developed and emerging equity markets, whereas the latter state that the lack of contagion is a general result for the CDS market of the 31 developed and emerging countries considered. Additionally, Mollah et al. (2016) highlight the key role of bank risk transfer between US and other countries as a driver of contagion.

\section{Conclusions}

We systematically review 45 finance papers on emerging market contagion from the 1990s through the 2007-2009 global financial crisis to the present in order to clarify what we have learnt about the emerging economies transmission relationships and to identify some remaining gaps. Given the extensive literature regarding financial contagion, our theoretical framework is focused on finance studies that analyse this topic in terms of cross-market linkages that reflect significant changes in financial asset correlations during crisis periods or transcend what is justified by the fundamentals.

In this sense, we find that the emerging market contagion literature has done a good job and numerous significant contributions exist on this topic. Even though several authors disagree, much consensus has emerged regarding the evidence of contagion. However, we do still find a few contradictory results, for example in the sources of the contagion relationships or the economic fundamentals and regional effects used. We observe that, even using the same contagion approach, the differences could be related to the methodology used or the sample specified, which could invalidate the robustness of the results. Therefore, more emerging markets contagion analyses are needed.

Given that a large sample of papers finds significant market transmission during crises, academia should be focused not only on distinguishing the concrete existence of this transmission across countries or regions, but also on examining what the specific channels of contagion are. Specifically, we think that it may be of interest to address a connected topic that has not received too much attention in the literature: studying the evidence about contagion in emerging economies by distinguishing between systematic and idiosyncratic contagion in order to see if the contagion effect is linked to global emerging factors (systematic contagion) or to specific emerging factors (idiosyncratic contagion).

In addition, the vast majority of studies on contagion in emerging economies focus on analysing the stock, bond and exchange rate market. However, it would be worthwhile to analyse contagion using high frequency data. Although the papers have mostly used daily and weekly data, the information regarding transmission between countries with high frequency financial data could be useful.

The global financial crisis has led to another important strand of the literature about credit risk transmission. Many researchers have become interested in understanding the dynamics of credit risk, paying special attention to developed countries, such as the US or Europe. However, given the importance of credit risk contagion, less attention has been paid to the analysis of sovereign credit risk transmission in the emerging economies. In this sense, the analysis of the contagion through the sovereign credit default swap market is an issue that we need to better understand.

\section{References}

Aloui, R., Ben Aïssa, M. S. B., \& Nguyen, D. K. (2011). Global financial crisis, extreme interdependences, and contagion effects: The role of economic structure? Journal of Banking \& Finance, 35(1), 130-141.

Ammer, J., Cai, F., \& Scotti, C. (2011). Has international financial co-movement changed? Emerging markets in the 2007-2009 financial crisis. Impact of the global financial crisis on emerging financial markets. 93. Impact of the global financial crisis on emerging financial markets (pp. 231-253).

Arestis, P., Caporale, G. M., Cipollini, A., \& Spagnolo, N. (2005). Testing for financial contagion between developed and emerging markets during the 1997 East Asian crisis. International Journal of Finance and Economics, 10(4), 359-367.

Arouri, M. E. H., Jawadi, F., \& Nguyen, D. K. (2010). International financial crisis and contagion. Dynamics of emerging stock markets: Empirical assessments and implications (pp. 185-202). .

Bae, K., Karolyi, G., \& Stulz, R. (2003). A new approach to measuring financial contagion. Review of Financial Studies, 16(3), 717-763.

Baig, T., \& Goldfajn, I. (1999). Financial market contagion in the Asian crisis. IMF Staff Papers, 46(2), 167-195.

Ballester, L., Casu, B., \& González-Urteaga, A. (2016). Bank fragility and contagion: Evidence from the bank CDS market. Journal of Empirical Finance, 38, 394-416.

Ballester, L., \& Gonzalez-Urteaga, A. (2017). How credit ratings affect sovereign credit risk: Cross-border evidence in Latin American emerging markets. Emerging Markets Review, 30, 200-214.

Beirne, J., \& Fratzscher, M. (2013). The pricing of sovereign risk and contagion during the European sovereign debt crisis. Journal of International Money and Finance, 34, 60-82.

Bekaert, G., Ehrmann, M., Fratzscher, M., \& Mehl, A. (2014). The global crisis and equity market contagion. The Journal of Finance, 69(6), 2597-2649.

Boyer, B., Kumagai, T., \& Yuan, K. (2006). How do crises spread? Evidence from accessible and inaccessible stock indices. Journal of Finance, 61(2), 957-1003.

de Boyrie, M. E., \& Pavlova, I. (2016). Dynamic interdependence of sovereign credit default swaps in BRICS and MIST countries. Applied Economics, 48(7), 563-575.

Calvo, S. G., \& Reinhart, C. M. (1996). Capital flows to Latin America: Is there evidence of contagion effects? Policy research working paper (pp. 1619). .

Caporale, G. M., Cipollini, A., \& Spagnolo, N. (2005). Testing for contagion: A conditional 
correlation analysis. Journal of Empirical Finance, 12(3), 476-489.

Caporin, M., Pelizzon, L., Ravazzolo, F., \& Rigobon, R. (2018). Measuring sovereign contagion in Europe. Journal of Financial Stability, 34, 150-181.

Celik, S. (2012). The more contagion effect on emerging markets: The evidence of DCCGARCH model. Economic Modelling, 29(5), 1946-1959.

Chan-Lau, J., Mathieson, D., \& Yao, J. (2004). Extreme contagion in equity markets. IMF Staff Papers, 51(2), 386-408.

Chiang, T. C., Jeon, B. N., \& Li, H. (2007). Dynamic correlation analysis of financial contagion: Evidence from Asian markets. Journal of International Money and Finance, 26(7), 1206-1228.

Cho, D., Choi, K., \& Chung, K. (2014). Interconnectedness and Contagion Effects in Asian Sovereign CDS Markets. 한국재무학회 학술대회 (pp. 285-307). .

Christoffersen, P., Errunza, V., Jacobs, K., \& Langlois, H. (2012). Is the potential for international diversification disappearing? A dynamic copula approach. The Review of Financial Studies, 25(12), 3711-3751.

Darolles, S., Dudek, J., \& Le Fol, G. (2013). Liquidity contagion. The emerging sovereign debt markets example. Paper presented at the 30th international French finance association conference.

Darolles, S., Dudek, J., \& Fol, G. L. (2015). Contagion in emerging markets. In N. Finch (Ed.). Emerging markets and sovereign risk (pp. 45-58). London: Palgrave Macmillan.

Dimitriou, D., Kenourgios, D., \& Simos, T. (2013). Global financial crisis and emerging stock market contagion: A multivariate FIAPARCH-DCC approach. International Review of Financial Analysis, 30, 46-56.

Dooley, M., \& Hutchison, M. (2009). Transmission of the U.S. subprime crisis to emerging markets: Evidence on the decoupling-recoupling hypothesis. Journal of International Money and Finance, 28(8), 1331-1349.

Dornbusch, R., Park, Y. C., \& Claessens, S. (2000). Contagion: Understanding how it spreads. The World Bank Research Observer, 15(2), 177-197.

Dungey, M., Fry, R., Gonzalez-Hermosillo, B., \& Martin, V. (2006). Contagion in international bond markets during the Russian and the LTCM crises. Journal of Financial Stability, 2(1), 1-27.

Dungey, M., \& Zhumabekova, D. (2001). Testing for contagion using correlations: Some words of caution (No. 2001-09). Federal Reserve Bank of San Francisco.

Eichengreen, B., Rose, A. K., \& Wyplosz, C. (1996). Contagious currency crises (No. w5681). National Bureau of Economic Research.

Fazio, G. (2007). Extreme interdependence and extreme contagion between emerging markets. Journal of International Money and Finance, 26(8), 1261-1291.

Fleming, J., Kirby, C., \& Ostdiek, B. (1998). Information and volatility linkages in the stock, bond, and money markets. Journal of Financial Economics, 49, 111-137.

Forbes, K., \& Rigobon, R. (2000). Contagion in Latin America: Definitions, measurement, and policy implications (No. w7885). National Bureau of Economic.

Forbes, K. J., \& Rigobon, R. (2002). No contagion, only interdependence: Measuring stock market comovements. The Journal of Finance, 57(5), 2223-2261.

Gupta, R., \& Guidi, F. (2012). Cointegration relationship and time varying co-movements among Indian and Asian developed stock markets. International Review of Financial Analysis, 21, 10-22.

Hassan, K., Hoque, A., \& Gasbarro, D. (2017). Sovereign default risk linkage: Implication for portfolio diversification. Pacific-Basin Finance Journal, 41, 1-16.

Horváth, R., Lyócsa, Š., \& Baumöhl, E. (2018). Stock market contagion in Central and Eastern Europe: Unexpected volatility and extreme co-exceedance. The European Journal of Finance, 24(5), 391-412.

Hwang, I., In, F. H., \& Kim, T. S. (2010). Contagion effects of the U.S. subprime crisis on international stock markets. Finance and corporate governance conference (pp. 1-45). .

Hyde, S., Bredin, D., \& Nguyen, N. (2007). Correlation dynamics between Asia-pacific, EU and US stock returns. Asia-Pacific financial markets: Integration, innovation and challenges. 8. Asia-Pacific financial markets: Integration, innovation and challenges (pp. 39-61).

Kaminsky, G. L., \& Reinhart, C. M. (2000). On crises, contagion, and confusion. Journal of International Economics, 51(1), 145-168.

Kaminsky, G. L., Reinhart, C. M., \& Vegh, C. A. (2003). The unholy trinity of financial contagion. Journal of Economic Perspectives, 17(4), 51-74.

Kang, H., \& Suh, H. (2015). Reverse spillover: Evidence during emerging market financial turmoil in 2013-2014. Journal of International Financial Markets Institutions and Money, 38, 97-115.

Kenourgios, D., \& Dimitriou, D. (2015). Contagion of the global financial crisis and the real economy: A regional analysis. Economic Modelling, 44, 283-293.

Kenourgios, D., \& Padhi, P. (2012). Emerging markets and financial crises: Regional, global or isolated shocks? Journal of Multinational Financial Management, 22(1-2), 24-38.

Kim, B. H., Kim, H., \& Lee, B. S. (2015). Spillover effects of the U.S. financial crisis on financial markets in emerging Asian countries. International Review of Economics and Finance, 39, 192-210.

Longstaff, F. A. (2010). The subprime credit crisis and contagion in financial markets. Journal of Financial Economics, 97(3), 436-450.

Luchtenberg, K. F., \& Vu, Q. V. (2015). The 2008 financial crisis: Stock market contagion and its determinants. Research in International Business and Finance, 33, 178-203.

Martin-Bujack, K., \& Corzo, M. T. (2016). Credit default swaps and financial risks in the 21 century.

Martinez, C., \& Ramirez, M. (2011). International propagation of shocks: An evaluation of contagion effects for some Latin American countries. Macroeconomics and Finance in Emerging Market Economies, 4(2), 213-233.

Masson, P. (1999). Contagion: Macroeconomic models with multiple equilibria. Journal of International Money and Finance, 18(4), 587-602.

Mollah, S., Quoreshi, A. M. M. S., \& Zafirov, G. (2016). Equity market contagion during global financial and Eurozone crises: Evidence from a dynamic correlation analysis. Journal of International Financial Markets Institutions and Money, 41, 151-167.

Naoui, K., Liouane, N., \& Brahim, S. (2010). A dynamic conditional correlation analysis of financial contagion: The case of the subprime credit crisis. International Journal of Economics and Finance, 2(3), 85-96.

Neaime, S. (2012). The global financial crisis, financial linkages and correlations in returns and volatilities in emerging MENA stock markets. Emerging Markets Review, 13(3), 268-282.

Ozkan, M. F. G., \& Unsal, D. F. (2012). Global financial crisis, financial contagion, and emerging markets. (No. 12-293). International Monetary Fund.

Park, Y., \& Song, C. (2001). Financial contagion in the East Asian crisis: With special reference to the republic of Korea. International financial contagion (pp. 241-265). .

Pericoli, M., \& Sbracia, M. (2003). A primer on financial contagion. Journal of Economic Surveys, 17(4), 571-608.

Reinhart, B. C. M., \& Rogoff, K. S. (2008). Is the 2007 US sub-prime financial crisis so different? An international historical comparison. The American Economic Review, 98(2), 339-344.

Rigobon, R. (2003a). On the measurement of the international propagation of shocks: Is the transmission stable? Journal of International Economics, 61(2), 261-283.

Rigobon, R. (2003b). Identification through heteroskedasticity. The Review of Economics and Statistics, 85(4), 777-792.

Rodriguez, J. C. (2007). Measuring financial contagion: A copula approach. Journal of Empirical Finance, 14(3), 401-423.

Samarakoon, L. P. (2011). Stock market interdependence, contagion, and the US financial crisis: The case of emerging and frontier markets. Journal of International Financial Markets Institutions and Money, 21(5), 724-742.

Samarakoon, L. P. (2017). Contagion of the Eurozone debt crisis. Journal of International Financial Markets Institutions and Money, 49, 115-128.

Stiglitz, J. E. (2010). Risk and global economic architecture: Why full financial integration may be undesirable. American Economic Review, 100(2), 388-392.

Tzeng, K., \& Tay, C. (2014). Transmission of the US subprime crisis and the European sovereign debt crisis to emerging markets. Journal of Applied Finance and Banking, 4(3), 217.

Yamamoto, S. (2014). Transmission of US financial and trade shocks to Asian economies: Implications for spillover of the 2007-2009 US financial crisis. North American Journal of Economics and Finance, 27, 88-103. 